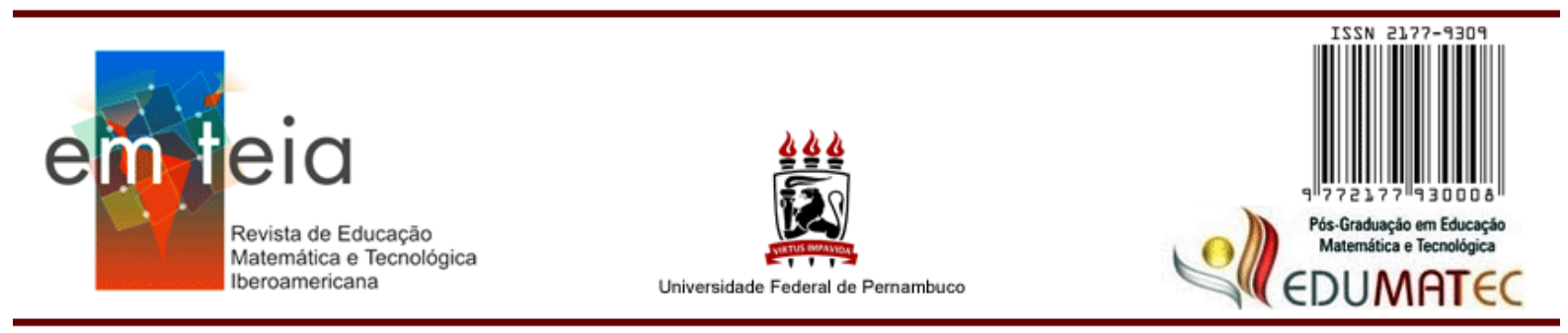

\title{
DESAFIOS DO ENSINO NA EDUCAÇÃO BÁSICA DE COMBINATÓRIA, ESTATÍSTICA E PROBABILIDADE
}

\section{Challenges of Teaching Combinatorics, Statistics and Probability in Basic Education}

\author{
Rute E. S. Rosa Borba \\ $\mathrm{PhD}$ pela Oxford Brookes University - Reino Unido \\ Universidade Federal de Pernambuco - PE - Brasil \\ resrborba@gmail.com \\ Leandro de Oliveira Souza \\ Doutorado em Ensino de Ciências e Matemática - Unicsul \\ Universidade Federal de Uberlândia - MG - Brasil \\ olilean@gmail.com \\ José Ivanildo Felisberto de Carvalho \\ Doutor em Educação Matemática - UNIAN \\ Universidade Federal de Pernambuco - PE - Brasil \\ ivanfcar@hotmail.com
}

\section{Resumo}

No presente texto apresentamos motivos para o aprendizado, na escolarização básica, de Combinatória, Estatística e Probabilidade. Discutimos, a partir de referenciais teóricos e de resultados de estudos empíricos, desafios específicos de cada uma dessas áreas e buscamos inter-relacionar os desafios entre si. Esperamos, desse modo, estimular a discussão de situações combinatórias, estatísticas e probabilísticas em salas de aula, incentivando um gradativo aprofundamento dos conceitos dessas áreas, desde o Ensino Fundamental até o Ensino Médio. Como finalidade tem-se o desenvolvimento cognitivo, conceitual, social e político dos estudantes, habilitando-os com robustos modos de raciocínio e a reflexão quanto à formação de professores para o ensino de Combinatória, Estatística e Probabilidade.

Palavras chave: Combinatória. Estatística. Probabilidade. Educação Básica.

\begin{abstract}
In this paper we present reasons for learning, in basic schooling, Combinatorics, Statistics and Probability. We discuss, from theoretical frameworks and results of empirical studies, specific challenges in each of these areas and seek to interrelate the challenges between them. We hope, therefore, to stimulate a discussion of combinatory, statistical and probabilistic situations in classrooms, encouraging a gradual deepening of the concepts of these areas, from Elementary School to High School. The purpose is to encourage cognitive, conceptual, social and political development of students, enabling them with robust modes of reasoning and reflection on teacher training for Combinatorics, Statistics and Probability.
\end{abstract}

Keywords: Combinatorics, Statistics, Probability, Basic Education. 


\section{INTRODUÇÃO}

Nesse texto apresentamos alguns desafios relativos a conteúdos mais recentemente introduzidos nos currículos de Matemática da Educação Básica. Nos Parâmetros Curriculares Nacionais (BRASIL, 1997, 1998) recomenda-se um novo eixo de conteúdos denominado Tratamento da Informação - o qual está orientado para o ensino e a aprendizagem de Combinatória, Estatística e Probabilidade, juntando-se aos mais tradicionais eixos de Números e Operações, Espaço e Forma (Geometria) e Grandezas e Medidas. Embora já se tenha passado 20 anos desde a proposta de se introduzir esse novo foco no Ensino Fundamental e no Ensino Médio, o estudo de situações combinatórias, estatísticas e probabilísticas ainda não é uma realidade em todas as salas de aula.

Os conteúdos desse eixo se fazem presentes no cotidiano dos estudantes da Educação Básica e são muito úteis ao desenvolvimento cognitivo dos mesmos. Há noções intuitivas que se desenvolvem independentes de instrução escolar, as quais podem servir de base para o aprendizado, mas há outros aspectos que carecem de ensino específico para o seu desenvolvimento.

No estudo da Combinatória, Estatística e Probabilidade, há conceitos complexos que se baseiam em formas elaboradas de pensamento analítico e hipotético-dedutivo. Essas áreas de estudo são, dessa forma, elementos centrais ao letramento matemático, envolvendo habilidades tais como: combinar elementos e levantar possibilidades; coletar, analisar e interpretar informações, bem como relacionar dados e comunicar conclusões a outras pessoas; e, também, tomar decisões diante de certezas e incertezas.

Acreditamos, assim, ser indispensável o desenvolvimento dessas formas de raciocínio combinatório, estatístico e probabilístico - como modo de visão ampla do mundo que nos cerca e para o exercício de cidadania plena, crítica e criativa. As habilidades envolvidas nesses raciocínios são muito necessárias nos dias atuais - com rápida circulação de um grande quantitativo de informações - sendo essenciais para compreensão e para mudanças das sociedades em que vivemos.

Nesse sentido, apresentamos alguns dos desafios que precisam ser alcançados para que o estudo da Combinatória, da Estatística e da Probabilidade seja foco desde o início até o final da escolarização básica. Embora os desafios sejam semelhantes nas três áreas, optamos por, incialmente, apresentar desafios específicos de cada área e, nas considerações finais, articular as questões postas, tornando mais evidentes as inter-relações entre essas áreas. 


\section{DESAFIOS DA COMBINATÓRIA}

Um dos maiores desafios da Educação Matemática é o de desenvolver nos estudantes da Educação Básica modos de raciocínio. Dentre as formas de pensamento a serem desenvolvidas, têm-se os raciocínios aritmético, geométrico, algébrico e combinatório - além de diversos outros. Desse modo, mais do que a aprendizagem de conteúdos matemáticos específicos, deseja-se que os estudantes da Educação Básica desenvolvam formas de pensamento que lhes sejam úteis para sua compreensão de mundo e para suas atuações na sociedade. $\mathrm{O}$ desenvolvimento de formas variadas de raciocínio tem grande impacto no bemestar das pessoas, por lhes possibilitar entendimento de suas realidades, para o desenvolvimento de pensamento crítico e criativo e para o pleno exercício da cidadania.

Nesse sentido, defendemos, como um primeiro desafio, o da abordagem da Combinatória desde o início da escolarização. Embora a Análise Combinatória seja conteúdo formalmente trabalhado no Ensino Médio, se há um desejo de desenvolver amplamente o raciocínio combinatório de estudantes, acreditamos que é preciso iniciar bem mais cedo o pensar e tratar de situações combinatórias. Não se pode esperar que essa forma de pensamento - como nenhuma outra - se desenvolva apenas em um nível de escolaridade (BORBA, 2010). Faz-se necessário que o raciocínio combinatório (e de outros modos de pensar) seja tratado bem mais cedo, inclusive na Educação Infantil.

Pode parecer absurdo tratar a Combinatória com crianças bem novas, mas estudos como os discutidos a seguir - têm evidenciado que desde o início da escolarização esse trabalho é possível. Obviamente não se deseja ensinar fórmulas às crianças, mas trabalhar situações combinatórias adequadas (com número baixo de possibilidades e por meio de recursos didáticos apropriados) é possível como apontado em estudos anteriores.

Pessoa e Borba (2012) propuseram variadas situações combinatórias para crianças da Educação Infantil e embora poucas das crianças levantaram todas as possibilidades de algumas das situações apresentadas, elas mostraram algumas compreensões em relação ao que estava sendo questionado. Por exemplo, ao serem solicitadas a escolherem três dentre quatro animais (cachorro, gato, papagaio e tartaruga), as crianças corretamente selecionavam apenas três animais, o que era evidência de que entendiam a relação de escolha dessa situação combinatória - uma combinação de quatro elementos, três a três.

Já outras relações combinatórias foram de difícil compreensão por parte das crianças. A relação de ordenação não foi entendida de imediato pelas crianças, pois, como se pode observar na Figura 1, elas escolhiam corretamente apenas três animais, mas não atentavam que havia possibilidades repetidas dentre as representadas. A possibilidade (cachorro, gato e papagaio) 
foi repetida três vezes, mostrando que a criança não atentou que nessa situação combinatória a ordem na qual as fichas fossem coladas não determinaria uma possibilidade distinta. Sendo um estudo de sondagem, não se teve, nesse momento, a intenção de ensinar as crianças, mas acreditamos que sendo questionadas, algumas das crianças perceberiam as repetições e poderiam ter entendido que nessa situação a ordem dos elementos não determina possibilidades distintas.

A relação de esgotamento de possibilidades, ou seja, levantamento de todas as possibilidades da situação combinatória, foi a mais difícil de ser compreendida pelas crianças. No exemplo aqui tratado (uma combinação), a criança deixou de elencar a possibilidade (gato, papagaio e tartaruga), embora tenha levantado as outras três possibilidades (cachorro, gato e papagaio), (cachorro, gato e tartaruga) e (cachorro, papagaio e tartaruga). Há evidência, assim, de muita compreensão da situação, embora não se tenha chegado ao número total de possibilidades.

Figura 1 - Resolução, por criança da Educação Infantil, de uma combinação de quatro animais, três a três.

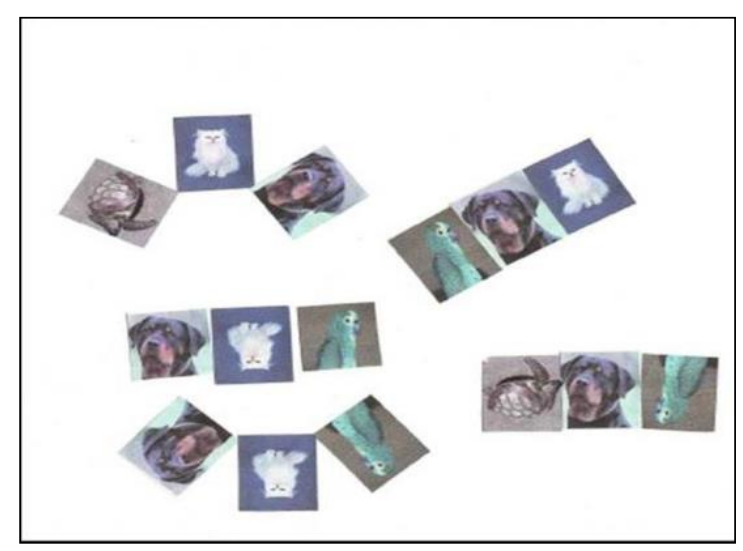

Fonte: Pessoa e Borba (2012).

Esse exemplo e outros (de produtos cartesianos, arranjos e permutações) que foram igualmente tratados junto a crianças de Educação Infantil nos mostram que é possível trabalhar situações combinatórias com crianças novas (de 5 e 6 anos de idade, por exemplo), desde que sejam situações simples, com poucas possibilidades a serem levantadas e a partir da manipulação de material, uma vez que as crianças em início de escolarização não dominam ainda outras formas de registro (como a escrita ou mesmo desenhos).

Dessa forma, entendemos que aceitar o desafio de início bem mais precoce da Combinatória pode ser uma boa medida para o desenvolvimento mais amplo do raciocínio 
combinatório. Isso porque os estudantes poderão ter contato constante (nos distintos níveis da Educação Básica) com esse tipo de situação e desenvolverão esse modo particular de raciocínio, com base em pensamento hipotético-dedutivo - no qual se levantam todas as possibilidades da situação combinatória a partir da análise de relações de escolha e de ordenação (e de outras relações, tais como proximidade, posicionamento, dentre outras, quando se trata de situações condicionais $\left.{ }^{1}\right)$.

O segundo desafio que desejamos levantar é o de utilizar representações simbólicas variadas para o trabalho com o mesmo conteúdo, podendo apresentar novas formas de registro ao longo da escolarização. Embora se destaque no ensino e na aprendizagem da Matemática o papel das representações simbólicas, acreditamos que esse papel precisa ser mais valorizado, uma vez que não há conceitualização sem representação simbólica e os registros adequados auxiliam no desenvolvimento conceitual.

Vergnaud (1986) dá um grande peso às representações simbólicas na conceitualização. Junto com as situações que dão significado aos conceitos e as relações associadas ao conceito (por ele denominadas de invariantes), Vergnaud inclui os símbolos utilizados na representação dos conceitos. A representação simbólica auxilia a perceber relações comuns a campos de conceitos e também a entender diferenças entre distintos conceitos, bem como ajuda no trato de muitos dados presentes em problemas a serem resolvidos.

Duval (2012) reforça a importância dos registros de representação semiótica no aprendizado matemático. Segundo esse autor, há necessidades de uma variedade de registros de um conceito para que não se confundam as representações com o próprio conceito. Desse modo, o uso de diversos registros possibilita que o estudante compreenda o conceito e não apenas manipule registros específicos do conceito. Nesse sentido, Duval aponta a necessidade das transformações de registros na aprendizagem da Matemática: conversões (de uma forma de registro a outro) e tratamentos (dentro de um mesmo modo de registro).

No caso específico da Combinatória, pesquisas - tais como as apontadas em Borba, Rocha e Azevedo (2015) - têm mostrado que um caminho de uso de representações simbólicas é: iniciar com o uso de material que as crianças possam manipular no levantamento de possibilidades (tais como brinquedos, fichas com desenhos ou fotos, dentre outros materiais); em seguida, solicitar que as crianças façam desenhos das situações combinatórias ou que listem as possibilidades; mais adiante podem sintetizar/sistematizar esses levantamentos por intermédio de diagramas, quadros e árvores de possibilidades; simultaneamente podem utilizar

\footnotetext{
${ }^{1}$ Para maior detalhamento das relações combinatórias condicionais ver Borba e Braz (2012).
} 
expressões numéricas para o cálculo do total de possibilidades solicitadas; essas expressões podem, em seguida, ser associadas ao princípio multiplicativo ${ }^{2}$; e, por fim, pode-se chegar às fórmulas de arranjos, combinações e permutações.

Na Figura 2 têm-se exemplos de representações geradas por estudantes para a resolução de uma situação combinatória. Estimular esse uso variado de representações é um modo de auxiliar os estudantes a pensarem sobre distintos tipos de problemas de Combinatória e a gerar resoluções baseadas em compreensão das situações postas.

Figura 2 - Resoluções, por estudantes de diferentes níveis de ensino, de um produto cartesiano (duplas de meninos e meninas para dança de quadrilha).
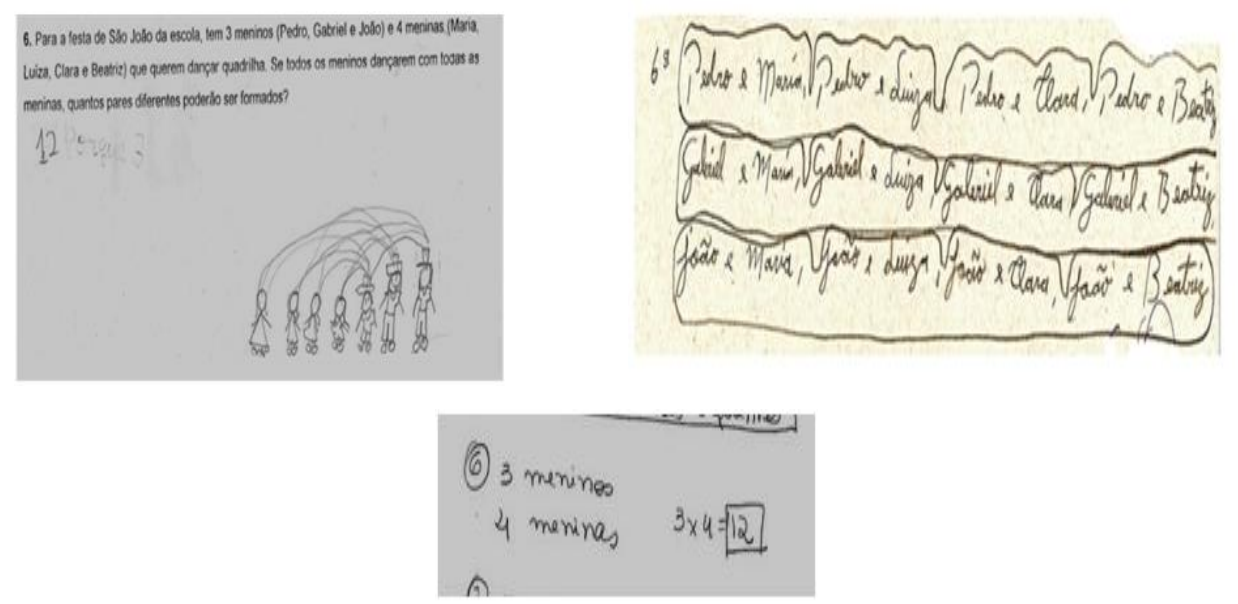

Fonte: Pessoa e Borba (2009).

Esse segundo desafio está intrinsecamente associado ao primeiro desafio, pois o início mais precoce do estudo da Combinatória possibilitará que diferentes formas de representação simbólica sejam utilizadas ao longo da escolarização. Assim, modos adequados de registro poderão ser utilizados nos distintos níveis de ensino e os estudantes poderão perceber aspectos comuns e diferenciadores entre os mesmos - possibilitando uma mais ampla compreensão das situações combinatórias e dos modos de representação das mesmas.

Outros desafios a serem enfrentados no ensino e na aprendizagem da Combinatória são: articular conceitos envolvidos em situações combinatórias com outros conceitos matemáticos; articular formação inicial e continuada de professores de distintos níveis de ensino, de modo que atuem como uma equipe corresponsável, que se valoriza mutuamente e que busca o

\footnotetext{
${ }^{2} \mathrm{O}$ enunciado do princípio multiplicativo, também conhecido como Princípio Fundamental da Contagem, é: "Se uma decisão D1 pode ser tomada de p modos e, qualquer que seja esta escolha, a decisão D2 pode ser tomada de q modos, então o número de maneiras de se tomarem consecutivamente as decisões D1 e D2 é igual a pq" (LIMA; CARVALHO; WAGNER; MORGADO, 2006, p. 125).
} 
desenvolvimento de formas de raciocínio dos estudantes; e lutar por políticas públicas que tenham como prioridade o desenvolvimento de modos de pensamento.

\section{DESAFIOS DA ESTATÍSTICA}

Criar gráficos e tabelas nos dias de hoje pode ser encarado como uma tarefa fácil, devido à possibilidade de transitar entre as diferentes representações com apenas um clique. No entanto, para conduzir situações de investigação e ser considerado alfabetizado estatisticamente, é necessário mais do que saber criar gráficos e tabelas, é preciso saber ler, analisar, compreender e resumir dados de modo que se possa contar algo sobre eles. Ser letrado vai além: é preciso ser capaz de utilizar diferentes ferramentas escritas. Entendemos que uma educação emancipatória, crítica e política deve ter foco no letramento. A estatística é uma das ferramentas necessárias para o letramento.

Friel, Cursio e Bright (2001) afirmam que os educadores têm muito a aprender sobre os processos envolvidos na leitura, na análise e na interpretação de informações apresentadas estatisticamente. Se levarmos em consideração a produção de informações por meio de investigações com coleta de dados, os obstáculos seriam maiores. Entendemos que fazer transições entre diferentes representações é extremamente importante durante o processo de aprendizagem, e devemos fazer isso, ao vincular a aprendizagem aos contextos dos dados (HENRIQUES; OLIVEIRA, 2012) ensinando estudantes a contar histórias embasados por dados e embasados em informações coletadas por eles.

De acordo com Pfannkuch, Regan, Wild e Horton (2010), o desenvolvimento de habilidades para contar histórias estatísticas é desafiado pelas práticas atuais de ensino. Isso ocorre porque, durante o processo de ensino, deve haver um debate aberto sobre o que constitui uma boa verbalização embasada na estrutura de gráficos e tabelas. Os professores precisam estar atentos a quais conceitos deveriam ser trazidos para a atenção dos estudantes e à forma como fazê-lo. Isso inclui atentar à linguagem, invocar pensamentos descritivos e inferenciais, compreender o contexto, delimitar a abrangência da situação estudada, determinar informalmente se as alegações podem ser feitas sobre as populações a partir dos dados da amostra e raciocinar por diferentes prismas, questionando suas próprias afirmações.

É preciso ajudar os estudantes a melhorar suas habilidades de relacionar informações; suas capacidades de filtrá-las e de extrair significados; e, por último, sua capacidade comunicativa. Na maior parte das vezes, a atenção, no trabalho pedagógico, fica concentrada na capacidade técnica dos estudantes, porém acreditamos ser possível desenvolver concomitantemente a capacidade comunicativa. Fazer isso é de extrema importância para a 
emancipação política e a formação da consciência dos sujeitos. É uma forma de ajudar a construir uma sociedade mais crítica e participativa. Nesse sentido, a educação estatística pode ser de grande ajuda. Nesse texto faremos uma relação sobre o ensino por meio de projetos e o conceito de insubordinação criativa. $\mathrm{O}$ desafio proposto para estudo nesse texto tem no cerne a flexibilidade do currículo a partir de uma aprendizagem mais ativa, com os estudantes no centro do processo educacional. A ideia que propomos é permitir que os estudantes, independentemente da faixa etária, atuem de forma investigativa para compreender seus contextos sociais e agir sobre eles.

\section{O conceito de insubordinação criativa e a sua relação com projetos de Educação}

\section{Estatística}

Estar à frente da execução de políticas força os profissionais da educação a enfrentar situações em que precisam tomar decisões rápidas, sem planejamento, sem informações sobre os sujeitos envolvidos, sobre o contexto ou sobre causas de conflitos, de modo que não lhes é possível compreender as demandas em profundidade ou analisar os méritos das suas decisões. Ao tomar decisões nessas condições, dificilmente irão atender às expectativas e necessidades das populações periféricas e marginalizadas. Em todos os casos, ações simplificadas e ou padronizadas podem tornar-se problemáticas e causar prejuízo às relações, principalmente quando partem do senso comum ou quando são fundamentadas em situações de desigualdade, estereótipos, preconceitos, rótulos, modelos ou trivialidades construídas socialmente ou culturalmente. Tais circunstâncias, via de regra, compõem o cenário das escolas em que atuam profissionais com pouco preparo para contrapor-se a elas, para insubordinar-se.

A insubordinação criativa, de acordo com D'Ambrosio e Lopes (2015), é um conceito que surgiu em 1981, quando Morris et al. publicaram um estudo etnográfico realizado com diretores de escolas americanas que utilizavam estratégias não usuais para romper com a burocracia e adaptar políticas públicas em prol de um melhor atendimento às necessidades da comunidade local. Havia um entendimento de que a padronização das políticas engessava as ações na escola, enquanto o excesso de tentativas de aprimoramento seria desorientador e contraproducente.

Para compreender o conceito de insubordinação criativa, é preciso primeiro partir da premissa de que esse conceito não considera a ideia única de desobediência segundo o senso comum. A insubordinação criativa se dá na interação do profissional que presta serviço público com a população, ao enfrentar estereótipos e fundamentações preconcebidas. A insubordinação 
criativa é um componente da tomada de decisão discricionária (HAYNES; LICATA, 1995) pelo profissional, a qual, segundo esses autores, se distingue do ato administrativo vinculado.

De acordo com Göttems (2012), os atos discricionários são aqueles que os agentes públicos podem praticar com liberdade, ou seja, fazem a escolha do seu conteúdo, de seu destinatário, de sua conveniência, de sua oportunidade e do modo de sua realização. Isso não significa a inexistência de lei, mas a lei permite ao agente que a prática do ato se dê pela maneira e nas condições que sejam mais convenientes ao interesse público.

$\mathrm{O}$ ato discricionário, por um lado, permite que o agente público tome decisões administrativas com liberdade. Por outro, quando essas decisões não se pautam em valores de solidariedade e justiça social, podemos ter indícios de opressão ou dominância por parte do sujeito legitimado para a função de executar o ato. Isso acaba por gerar conflitos ou inutilidade do serviço prestado.

De acordo com Gutiérrez (2013), ensinar Matemática não é uma atividade política neutra. D’Ambrosio e Lopes (2015) afirmam que, no ensino da Matemática, as ações de insubordinações criativas são identificadas quando o professor decide: romper com os discursos generalizadores; analisar os resultados dos estudantes como objeto de análise para melhorar a aprendizagem, desprezando ferramentas de quantificação de habilidades; argumentar para explicar as diferenças de aproveitamento dos alunos, usando discursos fora dos padrões de simplificação; questionar as formas como a Matemática é culturalmente apresentada na escola; enfatizar a incerteza da disciplina de Matemática e sua construção histórico-cultural; posicionar os alunos como autores da Matemática; e desafiar os discursos discriminatórios sobre os alunos.

A Matemática e a Estatística são ferramentas poderosas do mundo capitalista, porque fundamentam informações de vários setores. É por isso que ambas transmitem status na sociedade, o que, de acordo com Gutiérrez (2013), deveria nos levar a ser mais conscientes sobre o que pedimos para os alunos fazerem durante as aulas. De fato, muitos professores (e pesquisadores) reproduzem modelos de ensino autoritários, repugnam o papel político de sua função e daquela que a Matemática exerce na sociedade. Esses profissionais são pouco conscientes de sua incumbência e tornam-se cúmplices da reprodução da matemática como forma de microagressão.

Gutiérrez (2013) também argumenta que todo o ensino da matemática é um ato político, porque professores de matemática trabalham identidades, mesmo ao considerarem que não. A contribuição sobre a identidade dos alunos ocorre quando os professores reproduzem o que a matemática é, dando ênfase à forma como as pessoas poderiam se relacionar com ela (ou não). A relação que pretendemos estabelecer nesse texto entre a insubordinação criativa e a Educação 
Estatística visa desmistificar a passividade política do ensino de Matemática. Entendemos que essa possa ser uma ferramenta poderosa para ajudar crianças e adolescentes a produzirem informações para resolver problemas do seu próprio contexto, argumentando e comunicando sobre eles.

Relataremos nesse artigo um projeto de pesquisa que buscou o desenvolvimento de novas abordagens para o ensino de Estatística, por meio de atividades de investigação, exploração, tratamento e análise de dados, ao mesmo tempo que fornecia ferramentas para estudantes agirem politicamente dentro de uma escola. A questão que conduziu a pesquisa e entendemos ser um desafio foi: como preparar estudantes para compreender conceitos estatísticos e produzir informações, ao invés de apenas consumi-las?

Em busca de respostas para essa pergunta, conduzimos uma formação de um ano, com encontros quinzenais de aproximadamente duas horas, que envolveram dois alunos do Ensino Médio com bolsas de estudo do Edital PIBIC-JR CNPQ. Para fins de pesquisa, a coleta de dados deu-se por videogravação de entrevistas e das atividades desenvolvidas na formação, fotografia dos cadernos dos alunos, arquivos produzidos por eles em softwares específicos, relatórios semanais dos encontros e materiais produzidos pelos alunos durante o planejamento e a execução de um projeto elaborado e aplicado por eles na escola em que estudavam.

A aprendizagem nesse contexto foi construída de maneira dialética, com o pesquisador estimulando o raciocínio e a verbalização dos alunos por meio de perguntas durante a interação. Neste artigo, será narrado um recorte do projeto de pesquisa com ênfase na atuação de dois alunos do $2^{\circ}$ ano do Ensino Médio. Os estudantes apropriaram-se de ferramentas estatísticas, definiram um tópico de pesquisa, planejaram ações e organizaram informações para convencer a comunidade escolar e o diretor da escola a refletir sobre um problema local com relação à merenda escolar.

\section{Um problema do contexto dos estudantes: o restaurante escolar, o desperdício de alimentos e a formação política}

Depois de seis meses de formação, onde os estudantes foram expostos a diferentes ferramentas e conceitos estatísticos, pedimos a Andreia e Ronaldo ${ }^{3}$ que escolhessem um tema de seu interesse para ser investigado. A temática deveria emergir de algum problema dentro da escola. Foi explicado que a princípio não pensaríamos em gráficos, tabelas e nem em Estatística.

\footnotetext{
3 Trata-se de nomes fictícios.
} 
Exploraríamos a problemática para verificar se, ao final, poderíamos produzir algum tipo de informação. Explicamos que deveriam produzir um relatório sobre a problemática.

Os estudantes apontaram que um dos problemas na escola era a comida servida durante os intervalos. Andreia relatou que na última semana havia sido servida sopa todos os dias. Ronaldo concordou que esse era um problema, já que muitas pessoas reclamam do cardápio e, principalmente, da sopa. Perguntamos se conseguiriam produzir alguma informação sobre esse assunto. Ambos concordaram que seria um bom tema. Continuamos conversando sobre o assunto. Queríamos saber se eles achavam que havia desperdício de merenda.

Questionamos se seria possível medir o desperdício. Ronaldo disse que não haveria problemas, deveriam ficar durante o intervalo observando e, ao final, para verificar, colocariam os restos em um saco plástico e depois em uma balança. Questionamos também sobre quem eles achavam que desperdiçava mais comida, os meninos ou as meninas. Ronaldo acreditava que eram os meninos. Andreia concordou e, além disso, inferiu que parecia que eles frequentavam mais o refeitório do que elas. Ronaldo discordou, pois acreditava que a frequência era igual. Para saber qual gênero desperdiçava mais, chegamos à conclusão de que seria necessário dividir os restos em baldes diferentes. Os estudantes perceberam que precisariam de ajuda de funcionários da escola, de professores e, provavelmente, da direção da escola.

Outra preocupação discutida foi a gestão financeira dos alimentos. Andreia afirmou que havia ouvido que a escola recebia em torno de $\mathrm{R} \$ 0,30$ por aluno/dia para compra da merenda. Na conversa, concluímos que esse valor não era suficiente para a alimentação, e que provavelmente a escola administrava o dinheiro comprando alimentos mais baratos ou contando com o fato de que muitos alunos não comiam. Ronaldo disse acreditar que muitos estudantes não comiam na escola por vergonha, e outros poderiam estar desperdiçando os alimentos por ficarem constrangidos de serem julgados por colegas pela quantidade que comiam.

Ronaldo acreditava que o desperdício dependia da qualidade servida no dia. Ele comparou arroz e macarrão e citou que muitas vezes o macarrão era servido sem tempero, o que fazia as pessoas jogarem fora. Ele acreditava que o desperdício da sopa era menor do que nos outros dias, porque somente as pessoas que queriam comer sopa frequentavam o refeitório, ou seja, a sopa diminuía o consumo de alimento no dia que era ofertada. Foi pedido que anotassem que era importante descobrir qual alimento causava maior desperdício. Ao final do encontro, Ronaldo relatou que esse assunto era discutido todos os anos, no entanto, não havia transparência. A direção da escola perguntava sobre a preferência dos estudantes, mas nunca havia uma devolutiva para eles. A conversa continuou sobre os funcionários. Os estudantes relataram que as mesmas pessoas que trabalhavam na limpeza eram as que ajudavam na 
cozinha. Informaram que usavam toucas, mas não luvas para servir. Também especulamos sobre outros assuntos (formação, higiene etc.).

\section{Os objetivos da investigação e o plano de ação}

Andreia relatou que gostaria de conversar com a diretora da escola e explicar a ela o que pretendiam fazer durante o projeto. Ronaldo sugeriu que o Grêmio da escola também poderia ser convidado para participar. Pedimos que, antes de iniciarem os contatos, escrevessem sobre os objetivos da investigação. Andreia revelou que já havia se antecipado e escrito alguns tópicos sobre o que poderiam fazer. Solicitamos que ela os resumisse em uma frase, e ela respondeu que o objetivo seria evitar o desperdício de alimentos.

Questionamos se isso não seria o objetivo final e se eles não estavam se antecipando ao dizer que havia desperdício de alimentos. Ronaldo disse que, com certeza, havia desperdício de alimentos. E relatou que tinha comido no refeitório naquele dia e, sentado ao lado do cesto de restos para observar, avaliou que a comida estava boa, mas notou que havia na fila algumas pessoas que depois jogavam comida fora. Perguntamos então se ele poderia dizer quanto. Ele ficou em dúvida e disse que a quantidade poderia variar. Pedimos que Andreia fizesse novamente a leitura do objetivo e, ao invés de utilizarem o verbo "evitar" empregassem um outro que desse a ideia de que iríamos investigar a situação. Ronaldo perguntou se poderíamos usar o verbo analisar e continuou: "Analisar se existe desperdício de alimentos na escola para traçar estratégias (levantar ações) de conscientização".

Ao longo dos encontros seguintes os estudantes traçaram estratégias de coletas de dados em duas etapas. Primeiro, fizeram uma lista de perguntas abertas aos estudantes e depois dessa lista fizeram perguntas que seriam direcionadas às cozinheiras.

Além das entrevistas, os estudantes traçaram um plano de ação em tópicos para coletar dados: colocar dois sacos separados, um para as meninas e outro para os meninos; saber quantos meninos e meninas se alimentam por dia; verificar se havia uma balança na escola; criar tabela com a quantidade de alunos por gênero e a quantidade de alimentos desperdiçados por gênero; saber qual é o peso do balde; criar uma tabela ou outro questionário para levantar dados estatísticos; anotar o tempo que os estudantes ficavam na fila.

\section{O projeto e as inferências dos estudantes}

Os estudantes, por iniciativa própria, marcaram e tiveram uma conversa com a diretora da escola. Ronaldo informou que até aquele momento a diretora não sabia que os estudantes estavam participando do projeto, mas ela ficou feliz com a iniciativa. Os estudantes 
questionaram se o cardápio da escola era fixo. A diretora explicou que, em razão da dificuldade de gestão financeira, apenas depois daquele mês a escola conseguiria fixar um cardápio semanal. Ao final da conversa, a direção solicitou aos estudantes que, antes de iniciar o projeto, levassem ao seu conhecimento as perguntas que pretendiam fazer e um plano de ação. A diretora disse a eles que ficaria feliz em assistir às suas apresentações, disponibilizaria os materiais necessários e ajudaria com o que fosse preciso para a execução. Ainda, de acordo com Andreia, sugeriu que verificassem a aceitação de cada alimento por dias da semana.

Os estudantes também tiveram uma conversa informal com os colegas de sala. Relataram que, nas conversas, a sopa era o alimento mais referido como rejeitado. Ronaldo justificou que era por causa do calor da região e porque a sopa era servida às 9h30m da manhã. Segundo ele, nesse horário o sol já estava quente e por isso ouvia muitas pessoas reclamando. Ronaldo supôs que o desperdício de sopa deveria ser menor porque poucas pessoas frequentavam o refeitório naquele dia e provavelmente elas gostavam de sopa. Andreia relatou que os estudantes apontaram também que o tempo de intervalo era muito curto para comer tinham 20 minutos -, e isso os obrigava a tomar uma decisão: ou comiam ou ficavam fora da sala. Na sua opinião, esse podia também ser um dos motivos de desperdício.

Os estudantes também fizeram entrevistas com as cozinheiras, e o que mais chamou a atenção de Ronaldo foi que, enquanto faziam a entrevista, as cozinheiras estavam comendo. Sem cerimônia, elas jogaram restos dos pratos no lixo, o que, para Ronaldo, era incoerente. Segundo ele, se elas não sabiam o quanto era suficiente colocar no seu próprio prato, como poderiam servir os alunos de maneira adequada? As cozinheiras informaram que os restos de alimentos eram utilizados para criação de porcos. Ronaldo e Andreia fizeram relação dessa situação com o curta-metragem Ilha das Flores ${ }^{4}$ a que assistiram. Outras situações foram também discutidas pelos estudantes, porém não serão reportadas aqui.

\section{Os resultados da pesquisa dos estudantes}

Andreia e Ronaldo optaram por começar a investigação no momento em que o cardápio da escola fosse definido. Essa foi uma sugestão também da direção. Para coletar dados, os estudantes usaram uma tabela diária que continha os seguintes campos: data, desperdício masculino, desperdício feminino, quantidade de meninos servidos, quantidade de meninas servidas, tipo de comida servida, total de pessoas e tempo na fila. Antes de iniciar a coleta de

\footnotetext{
${ }^{4}$ Esse curta trata do desperdício de alimentos no Brasil na década de 80 associada à pobreza e à fome que assolava o país.
} 
dados, para poder medir o desperdício corretamente, passaram nas salas explicando o projeto e orientando os colegas que os restos deveriam ser jogados nos baldes que estavam separados por gênero. Disseram que, desde o primeiro dia do projeto, observaram que não havia mais pratos sendo deixados nas mesas. Para medir o tempo de espera, entregavam um cartão para o último aluno e cronometravam quanto tempo levaria até ele chegar à mesa de servir.

Os estudantes coletaram dados por aproximadamente um mês, analisaram os dados, agruparam, fizeram gráficos e no final produziram um relatório sobre suas observações. A Tabela 1 é um exemplo do material produzido pelos estudantes.

Tabela 1: Consumo no restaurante escolar no período de maio e junho de 2017

\begin{tabular}{|c|c|c|c|c|c|c|c|}
\hline Refeição & $\begin{array}{l}\text { Números de } \\
\text { dias servidos }\end{array}$ & $\begin{array}{l}\text { Quantidade } \\
\text { de pessoas }\end{array}$ & $\begin{array}{l}\text { Média diária no } \\
\text { refeitório }\end{array}$ & $\begin{array}{c}\text { Desperdício } \\
\text { Total }(\mathrm{Kg})\end{array}$ & $\begin{array}{l}\text { Desperdício } \\
\text { Médio }\end{array}$ & $\begin{array}{c}\text { Tempo na fila } \\
\text { (min) }\end{array}$ & $\begin{array}{c}\text { Média de } \\
\text { tempo na fila } \\
\text { (min) }\end{array}$ \\
\hline $\begin{array}{c}\text { Arroz com linguiça, } \\
\text { cenoura ralada e } \\
\text { salada }\end{array}$ & 1 & 181 & 181 & 6,4 & 6,4 & 15 & 15 \\
\hline $\begin{array}{l}\text { Baião de três com } \\
\text { salada }\end{array}$ & 2 & 443 & 222 & 9,8 & 4,9 & 25 & 12,5 \\
\hline $\begin{array}{c}\text { Carne moída com } \\
\text { batata, cenoura, arroz } \\
\text { e feijão }\end{array}$ & 4 & 932 & 233 & 20,3 & 5,1 & 62 & 15,5 \\
\hline Galinhada & 2 & 438 & 219 & 7,7 & 3,9 & 27 & 13,5 \\
\hline Macarrão à Bolonhesa & 2 & 397 & 199 & 3,6 & 1,8 & 26 & 13 \\
\hline Pão com carne moída & 1 & 214 & 214 & 0 & 0 & 11 & 11 \\
\hline Polenta, arroz e feijão & 5 & 1019 & 204 & 33,1 & 6,6 & 80 & 16 \\
\hline Sopa & 6 & 759 & 127 & 24,1 & 4,0 & 55 & 9,2 \\
\hline Vaca atolada e salada & 2 & 461 & 231 & 16,5 & 8,3 & 35 & 17,5 \\
\hline Total & 25 & 4844 & & 121,5 & 4,5 & & \\
\hline
\end{tabular}

Além desses dados, os estudantes também verificaram o desperdício individual por gênero. Calcularam a média de desperdício por gênero, a média de frequência por gênero no refeitório, de tempo de espera e produziram diferentes gráficos. Ao final, os estudantes produziram um relatório final. A seguir, um trecho do relatório:

[...] Passando os dias, analisando tudo aquilo, pudemos ver que o tempo gasto na fila e o desperdício de alimento variavam bastante dependendo do tipo da refeição servida. Vários alunos antes mesmo de iniciar a refeição, jogavam parte da sua comida fora por não gostarem de algum alimento que havia sido colocado no seu prato. Quando o tempo era insuficiente, o desperdício parecia ser maior, pois frequentemente sobrava alunos que ficavam comendo após o término do intervalo, por isto muitos deles não terminavam de comer e acabavam jogando a comida fora.

Temos como exemplo os dias em que foram servidos no cardápio vaca atolada com salada. Essa foi a refeição que mais tomou tempo para ser servida e teve o maior índice de desperdício, comparando com as outras refeições. Observamos que muitos alunos, antes mesmo de começarem a comer, jogavam a salada fora. A maioria disse que não gostava de salada no meio da refeição ou porque a mesma estava sem tempero, muitos pediam para não colocar a salada. Os funcionários optavam por não tirar porque isso tomava tempo. 
Pudemos notar também que a sopa foi a refeição mais servida enquanto fizemos a pesquisa. Havia uma média muito menor de pessoas que frequentaram o refeitório, com relação ao desperdício não foi o menor nem o maior comparado as outras refeições. O tempo para servir era mais curto, já que o consumo era menor.

Em todos os tipos de comida a quantidade de meninas que se alimentavam eram sempre superior à quantidade de meninos, assim inicialmente achávamos que as meninas ao fim da pesquisa desperdiçariam mais que os meninos. Mas com os resultados que obtivemos, notamos que os desperdícios comparados por ambas as partes têm em si pouca diferença.

Durante a elaboração desse relatório, procuramos não fazer intervenções, para verificar se os estudantes haviam adquirido autonomia ao longo da pesquisa. Identificamos que os estudantes apropriaram-se de ferramentas estatísticas, definiram um tópico de pesquisa, planejaram ações, tiveram que negociar para conseguir apoio dos profissionais que atuavam na escola e organizaram informações para convencer a comunidade escolar e o diretor da escola a refletir sobre um problema local com relação à merenda escolar. O último passo desse projeto será a comunicação dos resultados, por parte dos estudantes, em diferentes ambientes, inclusive na escola. Entendemos que permitir a comunicação dos resultados é fundamental para formação política dos estudantes. Além disso, a aprendizagem a partir do envolvimento deles na resolução de um problema local é potencialmente uma ação geradora de justiça social.

\section{Desafios da Probabilidade}

No campo da psicologia, Piaget e Inhelder (1951) foram os pioneiros a desenvolver estudos concernentes à compreensão de crianças com diferentes idades sobre probabilidade. Esses investigadores, na década de 50, já apontavam para a necessidade de desenvolver o raciocínio das crianças frente a situações que envolvam a aleatoriedade.

Anos mais tarde, Fischbein (1975) explora os fundamentos do pensamento intuitivo e como o mesmo se relaciona com o raciocínio probabilístico. Fischbein (1975) afirma que não há necessidade de se esperar pela fase de adolescência para trabalhar com situações aleatórias e que as crianças podem adquirir intuições corretas sobre probabilidade.

Recentemente, Bryant e Nunes (2012) desenvolveram uma série de investigações que abordam a compreensão de crianças sobre probabilidade. No âmbito dessas investigações e na proposta de um programa de ensino, Nunes, Bryant, Evans, Gottardis e Terlektsi (2012) apontam quatro principais demandas cognitivas à compreensão de probabilidade (Figura 3). Justamente o primeiro desafio que apontamos refere-se a essas demandas cognitivas. 
A primeira demanda consiste em aprofundar a compreensão da noção de aleatoriedade distinguindo as diferentes características dos eventos aleatórios, como, por exemplo, aleatório versus determinístico, improváveis versus impossíveis, dentre outras.

Figura 3: Demandas cognitivas à compreensão de probabilidade

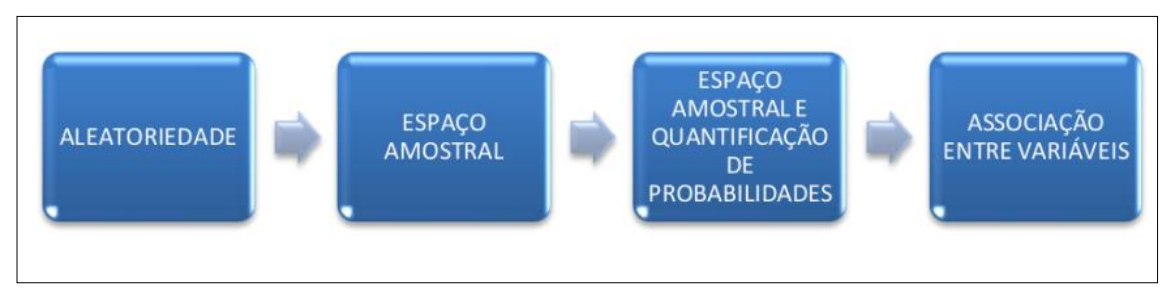

Fonte: Felisberto de Carvalho (2017 adaptado de NUNES et al., 2012).

A segunda demanda versa sobre considerações a respeito do espaço amostral. Apontamos a compreensão do espaço amostral como um passo importante na compreensão da resolução de problemas probabilísticos e que, muitas vezes, esse estudo é negligenciado.

Comparar e quantificar probabilidades se constituem na terceira demanda cognitiva. $\mathrm{Na}$ quantificação de probabilidades, temos que geralmente calcular a probabilidade ou comparar a força de duas ou mais probabilidades. Estes cálculos são de naturezas proporcionais desde que cada probabilidade é em si uma razão (entre um resultado específico e o conjunto de resultados possíveis). É preciso calcular as razões para poder realizar comparações de dois ou mais eventos. Atividades de comparação da melhor chance de um sucesso em um experimento aleatório podem ser trabalhadas com as crianças para desenvolver um melhor raciocínio probabilístico.

A quarta e última demanda consiste em compreender relações entre variáveis ou o estudo da associação entre variáveis. Esse estudo pode ser compreendido por meio da ideia de risco que Nunes et al. (2012) apontam como um aspecto importante do pensamento probabilístico. Os autores destacam ainda a importância de abordagem com representações que envolvam tabelas e gráficos. As tabelas de dupla entrada podem contribuir para compreender sobre a associação entre variáveis. Discorrem que problemas apresentados sob a forma de relação (por exemplo, $1: 3$ ) muitas vezes são mais fáceis para as crianças que os mesmos problemas apresentados como proporções de 1 (exemplo: 0,25) ou frações (1/4).

Estudos como os de Piaget e Inhelder (1951), Fischebein (1975) e Bryant e Nunes (2012), por um lado, nos apontam que é possível trabalhar desde os anos escolares iniciais com as noções de probabilidade e, por outro, fomentam - teórico e metodologicamente - outras pesquisas que nos brindam com ricos resultados e reflexões sobre o ensino e aprendizagem da probabilidade na Educação Básica. 
Poderíamos citar vários desses estudos, mas, por limitação, discorreremos sobre a investigação de Silva (2014). A autora optou por investigar as três primeiras exigências apontadas por Bryant e Nunes (2012). O objetivo foi analisar, em situações de jogos, conhecimentos de 36 crianças do $1^{\circ}, 3^{\circ}$ e $5^{\circ}$ anos do Ensino Fundamental. Dentre os resultados encontrados pela investigadora, as crianças conseguiram relacionar a aleatoriedade à sorte ou ao azar e demonstraram melhor compreensão em eventos pouco prováveis e em eventos impossíveis. As crianças demonstraram ainda fragilidades na compreensão de independência de eventos. No referido estudo também foram observadas dificuldades no mapeamento de espaços amostrais, como, por exemplo, a falta de percepção de que eventos tais como $3+5$ e $5+3$ são possibilidades distintas. Poucas crianças refletiram, conscientemente, sobre o espaço amostral para estabelecer a comparação de probabilidades.

As dificuldades de compreensão sobre probabilidade e as noções que sustentam esse conceito, como a aleatoriedade, não são exclusivas das crianças. Muitos pesquisadores citamos como exemplo Tversky e Kahneman (1974) - voltaram as atenções de seus estudos para tentar compreender como pessoas adultas lidam com as ideias de aleatoriedade e de probabilidade. Os autores discorrem que comumente as pessoas utilizam atalhos heurísticos que destoam dos conceitos e princípios elementares da probabilidade, levando a tomadas de decisões errôneas.

Um exemplo do nosso cotidiano são as situações em que as pessoas tiram conclusões e tomam decisões a partir de observações esparsas e insuficientes, tais como,

Ao considerar lances de uma moeda (assumidamente honesta) para obter cara $(\mathrm{K})$ ou coroa $(\mathrm{C})$, por exemplo, as pessoas encaram a sequência KCKCCK como mais provável do que a sequência KKKCCC, a qual não "parece" ser aleatória, e também como mais provável do que a sequência KKKKCK, que para elas não representa a imparcialidade da moeda. Desse modo as pessoas esperam que as características essenciais do processo estejam representadas não apenas globalmente na sequência inteira, mas também localmente em cada uma de suas partes (OLIVEIRA; CORDANI, 2016, p. 1272).

Essa concepção, segundo Mlodinow (2011), foi denominada como Lei dos Pequenos Números, pois este é um nome sarcástico para descrever a tentativa errônea da aplicação da Lei dos Grandes Números, em situações que envolvem um pequeno número de tentativas.

Outro aspecto que gostaríamos de enfatizar como um segundo desafio envolve os diferentes significados de probabilidade, a saber: intuitivo, clássico, frequentista, subjetivo e axiomático. Para Batanero (2005), o significado polifacético da probabilidade não pode ser negligenciado e que o ensino de probabilidade não se pode limitar a uma destas diferentes perspectivas, pela razão de estarem ligadas dialeticamente. Pesquisadores brasileiros (SILVA, 
2015; AMÂNCIO, 2012; COUTINHO, 1994) também apontam tal problemática com o ensino e aprendizagem da probabilidade e seus diferentes significados. Na década de 90, Coutinho (1994) já sugeria um trabalho com o enfoque frequentista "como sendo mais adequado e vantajoso para o ensino dos primeiros conceitos de probabilidade, uma vez que se podem utilizar experimentos ligados à realidade dos alunos, não precisando necessariamente estar limitado à hipótese de equiprobabilidade" (COUTINHO, 1994, p. 9).

Outra importante reflexão, um terceiro desafio, versa sobre a formação dos professores da Educação Básica e o conhecimento sobre probabilidade e sua didática. Com relação a esse desafio, ressaltamos algumas das problemáticas existentes. Há claramente a identificação que os professores que lecionam em distintos níveis escolares não contam com conhecimentos adequados sobre probabilidade e sua didática que os permitam desempenhar de maneira exitosa o ensino de probabilidade. Alguns estudos (SANTANA, 2011; DOLLARD, 2011; FELISBERTO DE CARVALHO, 2017) evidenciam que professores apresentam dificuldades e equívocos relacionados à compreensão do conceito de probabilidade e os diferentes significados, coadunando com pouca exploração desse conceito em sala de aula. Inclusive constata-se que professores que atuam no ensino elementar não estão familiarizados com a interpretação frequentista de probabilidade ou com a ideia de que se pode estimar a probabilidade de um evento através da experimentação; é forte a crença dos professores em validar a quantificação de probabilidades apenas por meio da probabilidade clássica. Os autores mencionam ainda as dificuldades de professores com alguns conteúdos como, por exemplo, o domínio do princípio multiplicativo e as dificuldades com o diagrama de árvore. Em uma pesquisa realizada por Rocha, Lima e Borba (2015), também sobre conhecimentos de professores, neste caso para o ensino de combinatória, esses pesquisadores apontam dificuldades dos professores com esses conteúdos, particularmente com o diagrama da árvore.

Neste ínterim, uma das razões que podemos apontar para os professores que ensinam matemática apresentar entraves com o conceito de probabilidade pode se dar por fortes crenças advindas do determinismo-matemático (SERRADÓ; CARDEÑOSO; AZCÁRETE, 2005) e que não os permitiram uma construção adequada das noções de aleatoriedade e probabilidade. Somando-se a isto, há também o fato de que os professores em seu curso de licenciatura apresentam pouca relação com conceitos tais como: variabilidade, acaso, aleatoriedade e incerteza. Destacamos que para compreender e interpretar as situações de probabilidade e estatística exige-se uma nova postura sobre a matemática, uma postura que seja diferente do olhar determinístico da matemática. 
Outro fato que pode decorrer do viés determinista da matemática é não considerar a importância da abordagem desta temática no chão da escola. Pietropaolo, Campos, Felisberto de Carvalho e Teixeira (2013, p. 2) argumentam que

muitos docentes sequer estão convencidos de que a probabilidade seja importante para ser desenvolvida no Ensino Médio; quanto ao Fundamental, têm uma posição ainda mais restritiva: consideram a inclusão desse tema totalmente inadequada e desnecessária.

Segundo Campos e Pietropaolo (2013, p. 59),

[...] para promover a inclusão da probabilidade no Ensino Fundamental, primeiro seria necessário convencer os professores de que a aprendizagem das noções relativas à probabilidade não é apenas útil para aplicação no cotidiano das pessoas, mas também pelo desenvolvimento de importantes habilidades cognitivas e de formas de pensar.

Diante do cenário por nós apresentado - e claro, não daremos conta de todas as questões que envolvem o ensino e aprendizagem da probabilidade -, procuramos destacar algumas indagações relevantes para a nossa reflexão. A primeira reflexão é de nos questionarmos, urgentemente, de como podemos abordar o ensino e aprendizagem da probabilidade com nossas crianças e adolescentes. E, neste sentido, algumas questões precisam ser por nós problematizadas, como, por exemplo: como partir das noções intuitivas dos estudantes e desenvolver o raciocínio probabilístico? Como entender o funcionamento das heurísticas no raciocínio dos estudantes com a tomada de decisões em situações de incerteza? Como considerar os diferentes significados de probabilidade? Como construir conexões entre a probabilidade e outros eixos da matemática? Como considerar a relação da probabilidade com a estatística na abordagem em sala de aula? E como utilizar diferentes recursos e as tecnologias para avançar na construção desse conhecimento?

A segunda reflexão remete às investigações que podem ser realizadas para compreender melhor os conhecimentos dos professores sobre a probabilidade e seu ensino. Ademais, que apoio os professores precisam para incorporar o trabalho com a probabilidade em suas salas de aula e como desenvolver processos formativos idôneos com os professores na formação inicial e continuada.

\section{Considerações Finais}

Os desafios apontados nas seções anteriores se inter-relacionam e, aqui, destacamos como se articulam, no sentido de promover avanços nos raciocínios combinatório, estatístico e 
probabilístico dos estudantes da escolarização básica. Ao discutir articulações, também apontamos implicações educacionais referentes às áreas de estudo aqui tratadas.

Resultados de pesquisas apontam que as compreensões de conceitos da Combinatória, da Estatística e da Probabilidade não são plenamente desenvolvidas sem instrução formal. Há noções intuitivas desenvolvidas fora da escola, mas até adultos escolarizados apresentam concepções errôneas no que diz respeito ao levantamento de possibilidades, à interpretação de informações e ao julgamento de determinismo de eventos. Desse modo, faz-se muito importante o estudo dessas áreas em aulas de Matemática.

Por envolverem relações complexas, é longo o tempo necessário para um mais amplo desenvolvimento dos raciocínios combinatório, estatístico e probabilístico. Assim, o estudo dessas áreas deve se fazer presente desde o início até o final da escolarização básica para possibilitar desenvolvimentos mais aprofundados. Resultados de diversas investigações, junto a crianças em início de escolarização, apontam que é possível o estudo da Combinatória, Estatística e Probabilidade nos primeiros anos do Ensino Fundamental, ou até mesmo na Educação Infantil, desde que as atividades sejam mais simples e em contextos significativos às crianças. Deve-se assumir o compromisso de criar ambientes educacionais em que haja apoio aos sujeitos, em que se potencialize o desenvolvimento do indivíduo como um ser viável, vibrante, criativo, moral, responsável, confiante, colaborativo, capaz de se preocupar com o bem-estar e a dignidade de todas as pessoas à sua volta.

No estudo dessas três áreas, tanto com crianças em início de escolarização, quanto com estudantes de outros níveis e modalidades de ensino, é essencial atentar ao importante papel que as representações simbólicas exercem no aprendizado da Matemática. Dessa maneira, variados registros - em linguagem natural (oral e escrita), em quadros, tabelas, gráficos e expressões numéricas (com números naturais e racionais, dentre outros) - devem ser utilizados no ensino e na aprendizagem da Combinatória, da Estatística e da Probabilidade. As transições entre os distintos registros são fundamentais ao aprendizado matemático e devem fazer parte das atividades desenvolvidas junto aos estudantes.

Também é preciso pensar em modos inovadores de tratar os conceitos matemáticos envolvidos nessas áreas. Recursos diversos podem ser utilizados, por intermédio de atividades de investigação, de levantamento de possibilidades, de discussão de hipóteses, de experimentação e de sistematização e comunicação de achados.

Não é por acaso que essas três áreas fazem parte de um mesmo eixo curricular. Essa inter-relação se dá por razões estruturais - tanto matemáticas, quanto cognitivas. Dessa maneira, o ensino dessas áreas precisa ser articulado, a partir de contextos que trabalhem 
simultaneamente situações combinatórias, estatísticas e probabilísticas. Essa articulação possibilitará que os estudantes percebam como as distintas áreas de estudo se inter-relacionam e como estão presentes em seus cotidianos.

Por se tratar de um eixo curricular mais recente, é preciso atentar para aspectos da formação inicial e continuada de professores que garantam maior segurança aos mesmos no tratamento desses conteúdos em sala de aula. Debates - tanto relativos aos conceitos, quanto ao ensino dos conceitos - são fundamentais, nos processos formativos, para que os professores se apropriem de como trabalhar a Combinatória, a Estatística e a Probabilidade em suas salas de aula.

Amplos debates referentes ao currículo e à avaliação são essenciais, de modo a se considerar o desenvolvimento de modos matemáticos de raciocínio e não apenas preocupar-se com conteúdos a serem abordados ou, menos ainda, meramente para o preparo de testes (internos e externos às escolas). Na discussão de currículos, avaliações e de variadas políticas públicas é necessário também o envolvimento de professores e estudantes da escolarização básica, de modo que não haja conformação com as realidades vivenciadas, mas também vontades e ações na direção de transformação de realidades.

\section{Referências}

AMÂNCIO, Juliana Ramos. Planejamento e aplicação de uma sequência didática para o ensino de probabilidade no âmbito do PIBID. 2012. 225 f. Dissertação (Mestrado em Ensino de Matemática) - Programa de Pós-graduação em Ensino de Matemática.

Universidade Federal do Rio de Janeiro, Rio de Janeiro, 2012.

BATANERO, Carmen. Significados de la probabilidad en la educación secundaria. Revista Latinoamericana de Investigación en Matemática Educativa. v. 8, n. 3, p. 247-263, 2005.

BORBA, Rute. O raciocínio combinatório na Educação Básica. $10^{\circ}$ Encontro Nacional de Educação Matemática - ENEM. Anais... Salvador, 2010.

BORBA, Rute; BRAZ, Flávia Myrella. O que é necessário para compreender problemas combinatórios condicionais? III Simpósio Internacional de Pesquisa em Educação Matemática - XIII SIPEMAT. Anais..., Fortaleza, CE, 2012.

BORBA, Rute; ROCHA, Cristiane; AZEVEDO, Juliana. Estudos em Raciocínio Combinatório: investigações e práticas de ensino na Educação Básica. Bolema. Boletim de Educação Matemática (UNESP. Rio Claro. Impresso), v. 29, p. 1348-1368, 2015. 
BRASIL. Ministério da Educação. Secretaria de Educação Fundamental. Parâmetros curriculares Nacionais Primeiro e Segundo ciclos do Ensino Fundamental: Matemática. Brasília: MEC, 1997.

Ministério da Educação. Secretaria de Educação Fundamental. Parâmetros curriculares Nacionais Terceiro e Quarto ciclos do Ensino Fundamental: Matemática. Brasília: MEC, 1998.

BRYANT, Peter; NUNES, Terezinha. Children's Understanding of Probability: a literature review. 2012. Disponível em: 〈www.nuffieldfoundation.org>. Acesso em: 10 jan. 2016.

CAMPOS, Tânia; PIETROPAOLO, Ruy Cesar. Um estudo sobre os conhecimentos necessários ao professor para ensinar noções concernentes à probabilidade nos anos iniciais. In: BORBA, Rute; MONTEIRO, Carlos (Orgs). Processos de ensino e aprendizagem em educação matemática, 1. Recife: Editora Universitária da UFPE, 2013. p. 55-61.

COUTINHO, Cileda Queiroz e Silva. Introdução ao conceito de probabilidade por uma visão frequentista - estudo epistemológico e didático. 1994. 151f. Dissertação (Mestrado em Educação Matemática) - Pontifícia Universidade Católica de São Paulo, São Paulo, 1994.

D’AMBROSIO, Beatriz Silva; LOPES, Celi Espasandin. Insubordinação criativa: um convite à reinvenção do educador matemático. Bolema, Rio Claro, v. 29, n. 51, p. 1-17, 2015.

DOLLARD, Clark. Preservice elementary teachers and the fundamentals of probability. Statistics Education Research Journal, v. 10, n. 2, p. 27-47, 2011.

DUVAL, Raymond. Registros de representação semiótica e funcionamento cognitivo do pensamento. Revemat: Revista Eletrônica de Educação Matemática. Florianópolis, v. 07, n. 2, p. 266-297, 2012.

FELISBERTO DE CARVALHO, José Ivanildo. Um estudo sobre os conhecimentos didáticos-matemáticos de probabilidade com professores de matemática dos anos finais do Ensino Fundamental. 2017. 344f. Tese (Doutorado em Educação Matemática) Universidade Anhanguera de São Paulo, São Paulo, 2017.

FISCHBEIN, Efraim. The intuitive sources of probabilistic thinking in children. Dordrecht, The Netherlands: Reidel, 1975.

FRIEL, Susan; CURSIO, Frances; BRIGHT, George. Making sense of graphs: Critical factors influencing comprehension and instructional implications. Journal for research in Mathematics Education, Reston, v. 32, n. 2, p. 124-158, 2001.

GÖTTEMS, Claudinei. Direito fundamental à educação. Argumenta Journal Law, Jacarezinho, v. 16, n. 16, p. 43-62, 2012.

GUTIÉRREZ, Rochelle. Why (urban) mathematics teachers need political knowledge. Journal of Urban Mathematics Education, Atlanta, v. 6, n. 2, p. 7-19, 2013. 
HAYNES, Eddy; LICATA, Joseph. Creative insubordination of school principals and the legitimacy of the justifiable. Journal of Educational Administration, Bingley - Inglaterra, v. 33, n. 4, p. 21-35, 1995.

HENRIQUES, Ana; OLIVEIRA, Helia. Investigações estatísticas: um caminho a seguir. Educação e Matemática, Lisboa - Portugal, v. 120, n. 1, p. 3-8, 2012.

LIMA, Elon; CARVALHO, Paulo; WAGNER, Eduardo; MORGADO, Augusto. Temas e problemas elementares. Sociedade Brasileira de Matemática - SBM, 12. ed. Rio de Janeiro, 2006.

MLODINOW, Leonard. O andar do bêbado: como o acaso determina nossas vidas. Rio de Janeiro: Zahar, 2011.

NUNES, Terezinha; BRYANT, Peter; EVANS, Deborah; GOTTARDIS, Laura; TERLEKTSI, Maria-Emmanouela. Teaching primary school children about probability. Teacher handbook. Departamento de Educação, Universidade de Oxford. [CD-ROM]. 2012.

OLIVEIRA, Claudio; CORDANI, Lisbeth Kaiserlian. Julgando sob incerteza: heurísticas e vieses e o ensino de probabilidade e estatística. Revista do Programa de Estudos PósGraduados em Educação Matemática, [S.1.], v. 18, n. 3, jan. 2016. ISSN 1983-3156. Disponível em: <https://revistas.pucsp.br/index.php/emp/article/view/31484>. Acesso em: 19 out. 2017.

PESSOA, Cristiane; BORBA, Rute. Quem dança com quem: o desenvolvimento do raciocínio combinatório de crianças de 1a a 4a série. Zetetike (UNICAMP), v. 17, p. 105-150, 2009.

PESSOA, Cristiane; BORBA, Rute. Do young children notice what combinatorial situations require? 36th Conference of the International Group for the Psychology of Mathematics Education (PME36), Proceedings...Taiwan, 2012.

PFANNKUCH, Maxine; REGAN, Matt; WILD, Chris; HORTON, Nicholas. Telling data stories: Essential dialogues for comparative reasoning. Journal of Statistics Education, Online American Statistical Association, v. 18, n. 1 p. 1-38, 2010.

PIAGET, Jean; INHELDER, Barbel. A origem da ideia do acaso na criança. Rio de Janeiro: Record, 1951.

PIETROPAOLO, Ruy Cesar; CAMPOS, Tânia; FELISBERTO DE CARVALHO, José Ivanildo; TEIXEIRA, Paulo. Um estudo sobre os conhecimentos necessários ao professor para ensinar noções concernentes à probabilidade nos anos iniciais. Anais do IV Seminário do Observatório da Educação da CAPES. Brasil, 2013.

ROCHA, Cristiane; LIMA, Ana Paula Barbosa de; BORBA, Rute. Conhecimentos de professores para ensinar combinatória: contribuições de pesquisas. Anais do VI Seminário Internacional de Pesquisa em Educação Matemática. Goiás, 2015. 
SANTANA, Michaelle. O acaso, o provável, o determinístico: concepções e conhecimentos probabilísticos de professores do ensino fundamental. 2011. 94f. Dissertação (Mestrado em Educação Matemática e Tecnológica ) - Programa de Pós-graduação em Educação Matemática e Tecnológica, UFPE, Recife, 2011. Disponível em:

http://www.gente.eti.br/edumatec/

SERRADÓ, Ana; CARDEÑOSO, José; AZCÁRATE, Pilar. Las concepciones deterministas, un obstáculo para el desarrollo profesional del docente en el campo probabilística. V Congreso Iberoamericano de Educación Matemática, Actas... Porto, 2005.

SILVA, César Diogo Bezerra da. Significados de probabilidade: uma análise em livros didáticos dos anos finais do ensino fundamental. 2015. 70f. Trabalho de Conclusão de Curso - Matemática-Licenciatura - UFPE - CAA, Caruaru, 2015.

SILVA, Rita de Cássia Batista da. É a moeda que diz, não é a gente que quer não: conhecimentos de crianças em situações de jogos. 2014. Dissertação (Mestrado em Educação matemática e Tecnológica ) - Programa de Pós-Graduação em Educação Matemática e Tecnológica - Edumatec, Recife, 2014. Disponível em: http://www.gente.eti.br/edumatec/

TVERSKY, Amos; KAHNEMAN, Daniel. Judgment under Uncertainty: Heuristics and Biases. Science, p. 1124-1131, 27 sep 1974.

VERGNAUD, Gérard. Psicologia do desenvolvimento cognitivo e didática das matemáticas. Um exemplo: as estruturas aditivas. Análise Psicológica, v. 1, pp. 75-90, 1986. 